\title{
Hazop Study Report Lpg Liquid Off Take System
}

\author{
* J. Karthi, G. Shangumasundar
}

Department of Mechanical Engineering, Sri Sai Ram Institute of Technology, Chennai, India.

*Corresponding author Email: sitp20is10@sairamtap.edu.in

\begin{abstract}
Hazard and Operability study (HAZOP) is a structured and systematic technique for system examination and risk management. In particular, HAZOP is often used as a technique for identifying potential hazards in a system and identifying operability problems. HAZOP is based on a theory that assumes risk events are caused by deviations from design or operating intentions. Identification of such deviations is facilitated by using sets of "guide words" as a systematic list of deviation perspectives. This approach is a unique feature of the HAZOP methodology that helps stimulate the imagination of team members when exploring potential deviations.

Keywords: Hazop, safety, risk
\end{abstract}

\section{Introduction}

The actual study must proceed in a carefully planned, systematic manner to cover all of the selected aspects of the process or operation by HAZOP team. It is normal to cover a continuous operation by dividing it into sections and working from an upstream starting point. To carry out a HAZOP study, Process flow diagram, Piping \& Instrumentation diagram (P\&ID), detailed equipment specifications, details of materials and material safety data sheet used are required. It must be collected by the HAZOP team before begin the study. The HAZOP team leader should ensure the availability of an adequately sized and skilled HAZOP team. A HAZOP team, at a minimum, should consist of a leader, a technical secretary, and two other individuals who have an understanding of the design and operation of the subject process. Ideally, the team consists of five to seven members, although a smaller team could be sufficient for a simpler, less hazardous plant. It is important to have certain people present, others are optional extras. However it is counterproductive to have more than six and seven, people at a review and so the Study Leader must look at the P and ID in advance of the HAZOP, and decide which engineers should be present for the particular study. In Liquid off Take (LOT) system, LPG cylinders are connected to the common manifold system in series, where liquid LPG withdrawn from cylinders using LOT valves \& is converted into vapor using a vaporizer. The converted LPG is discharged to the system for usage. It can be used for high rate consumption.

LPG LOT System is advance concept in Multi-cylinder Installation which offers Strength of Bulk LPG Installation and easy functionality. LPG LOT System can cater to volumes up to $250 \mathrm{Kg}$ per hour Installation which overcomes lots of problems and demerits of bulk LPG Installation \& conventional Manifold (VOT) system. LPG LOT System withdraws Liquid LPG up to $10 \mathrm{Kg} / \mathrm{Hr}$. LOT System is known for their compact design and safe usage. The systems offered comprise connecting hoses, NRVs, valves, piping system, LPG vaporizer with all safety fittings, pressure regulating stations, filters and gauges. HeaterlessVapourizer - It uses an innovative technology that does not use expensive electricity nor rely on natural vaporization. Making use of heater less vaporizers that works on the principle of thermodynamics, the pressure and temperature of LPG is reduced adiabatically. The system uses a special heat exchanger which works on continuous flow of water from a water storage tank in a closed loop circulation. The whole process converts LPG into vapor form at the required pressure. LOT system withdraws liquid LPG using LOT valves \& is converted into vapour using a vaporizer. LPG off take per cylinder can go up to $10 \mathrm{~kg} / \mathrm{hr}$ which is comparatively much more than the normal vapor off take cylinder of 0.6 $\mathrm{kg} / \mathrm{hr}$. The system offers the efficiency of Bulk installation and easy functionality of cylinder manifold system. LOT system is compact, safe \& highly cost effective as liquid is completely drawn from the cylinder and there is no residual loss.

\section{Identifying Causes}

Once a meaningful deviation has been identified, the team then seeks a cause. If there are likely to be several causes, as with the deviation „,no flow ${ }^{\text {ee }}$ in a pipeline, it is very helpful to have a short brainstorming session to identify as many causes as possible, remembering that causes may be related to human factors as well as to hardware items. In seeking causes (and evaluating consequences), it is essential that all members of the team take a positive and critical, but not defensive, attitude. The identified causes has to be discussed in detail, a judgment on this cannot be made without taking account of the nature and seriousness of the consequences. Acceptable 9 risks involve a trade-off between frequency and severity so it is impractical to completely separate the discussion of cause and consequences in a HAZOP analysis. 


\section{Methodology}

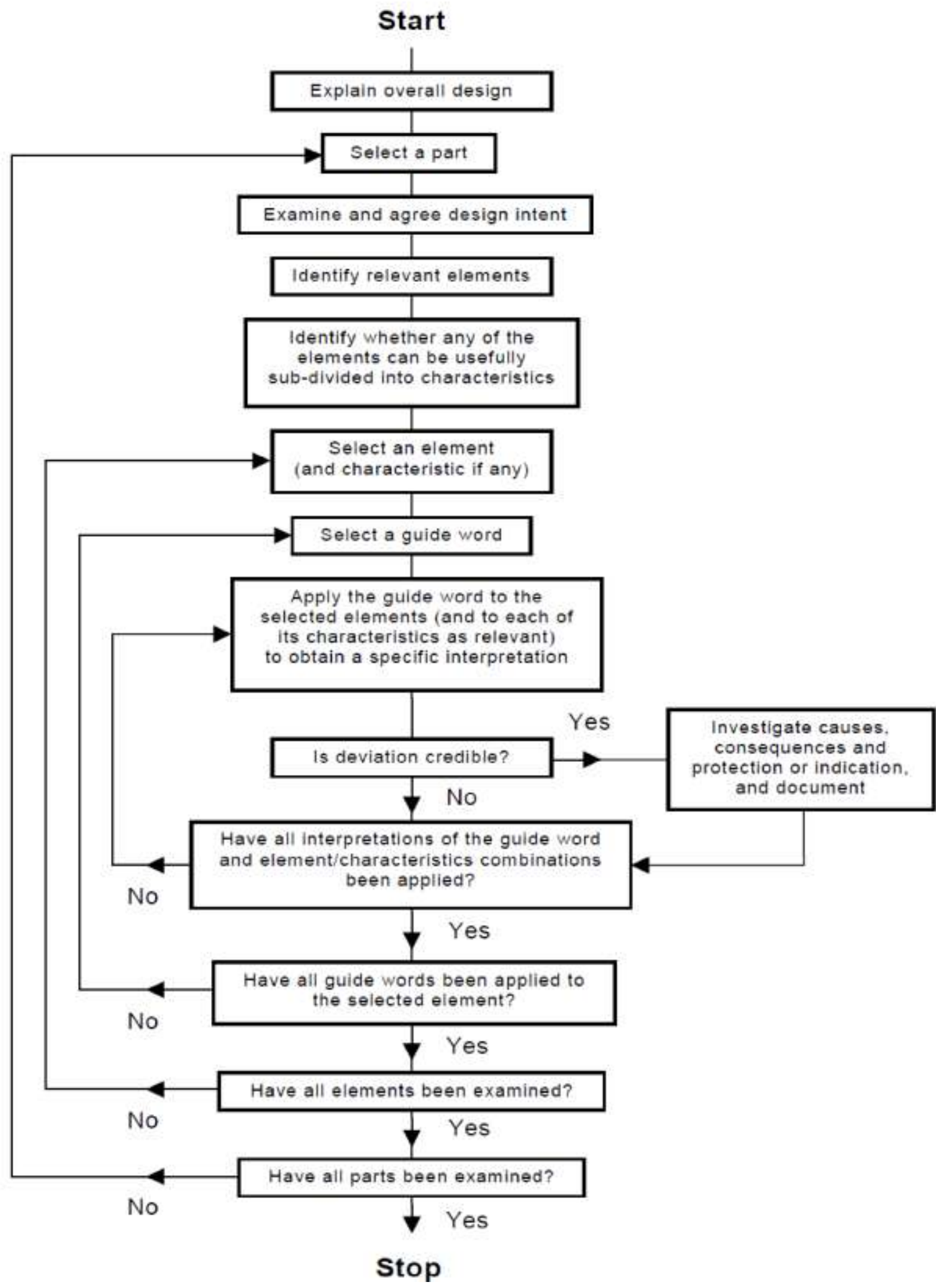

\section{Experimental Procedure}

The HAZOP team leader should ensure the availability of an adequately sized and skilled HAZOP team. A HAZOP team, at a minimum, should consist of a leader, a technical secretary, and two other individuals who have an understanding 
of the design and operation of the subject process. Ideally, the team consists of five to seven members, although a smaller team could be sufficient for a simpler, less hazardous plant. It is important to have certain people present, others are optional extras. However it is counterproductive to have more than six and seven, people at a review and so the Study Leader must look at the P and ID in advance of the HAZOP, and decide which engineers should be present for the particular study. It is essential the team begins with a full understanding of the section or stage to be analysed, either knowing the existing situation or having sufficient information to be able to form an adequate conceptual model. Afull description should be developed, including all the key parameters and the HAZOP report should reference the design description. A design intention for the step is formulated and recorded. This should include a statement of the intended operational range so that the team can recognize any situations lying outside this range as deviations. The next step is to generate a meaningful deviation by coupling a guideword and a parameter. A deviation can be generated by taking a parameter and combining it with each guideword in turn to see if a meaningful deviation results (the parameter approach). The alternative approach is to take a guideword and try each parameter in turn (the guideword approach). The standard set of guidewords for process plant is listed, along with the generic meanings. Asthe purpose of the guidewords is to assist the team in a creative and thorough search for meaningful deviations, it is important to select a set that works well for the problem being studied.

The consequences of each cause must be carefully analysed to see whether they take the system outside the intended range of operation. It is essential to fully identify all of the consequences, both immediate and delayed, and both inside and outside the section under analysis. It often helps to analyse how the consequences develop over a period of time, noting when alarms and trips operate and when and how the operators are alerted. This allows a realistic judgement on the likelihood and influence of operator intervention. There are variations in practice as to when the existing safeguards and protection are noted and taken into account. One approach is first to analyse the outcome ignoring the existence of any safeguards such as an alarm, trip or vent. This approach has the advantage that the team is alerted to possible serious consequences and misjudgments of the need for protection are less likely. Against this, it can be argued that it is unrealistic to ignore the inbuilt safeguards of a well-designed operation. Whichever approach is adopted, it is good practice to make note of the safeguards in the detailed records of the study. Several different approaches are in common use, after a potential problem is identified; it is always referred for investigation outside of the HAZOP meeting. At the other extreme, the team attempts, whenever possible, to deal with the problem and record a recommended solution to that problem whether engineering or procedural. The norm is for an intermediate approach where the team recommends a solution to the problem only if there is a breach of standards or if the team has unanimously agreed a solution which is within their authority to make. This approach has the benefit that agreed hardware changes can be immediately marked on the working drawing and taken into account during the remainder of the study. It is good practice to have an entry in the action column for every deviation and cause discussed, even if the entry simply states that no action is required because the existing safeguards are considered adequate.

\section{Conclusion}

The conclusions reached by the team must be fully recorded and it should be remembered that the HAZOP report typically represents the only comprehensive record of the study and of the operating strategy intended by the designers of the plant. The report should be regarded as one of the suite of key documentation handed forward to the operators of the project. The selection of items to be included in the record is agreed during the planning of the study. It is important that sufficient detail is recorded for the potential problem to be understood other persons. A formal must be prepared by the team and it must be reviewed by project manager.

\section{References}

[1]. "Energy and Air Pollution" (PDF). Iea.org. Archived from the original (PDF) on 11 October 2019. Retrieved 12 March 2019.

[2]. Mengoni, M., Matteucci, M., \&Raponi, D. (2017). A Multipath Methodology to Link Ergonomics, Safety and Efficiency in Factories. Procedia Manufacturing, 11, 1311- 1318.

[3]. Djapan, M., Macuzic, I., Tadic, D., \&Baldissone, G. (2018). An innovative prognostic risk assessment tool for manufacturing sector based on the management of the human, organizational and technical/technological factors. Safety Science.

[4]. Lee, K. S., \& Jung, M. C. (2015). Ergonomic evaluation of biomechanical hand function. Safety and health at work, 6(1), 9-17.

[5]. Chinniah, Y., Aucourt, B., \&Bourbonnière, R. (2017). Safety of industrial machinery in reduced risk conditions. Safety science, 93, 152-161.

[6]. "World's Most Polluted Cities in 2020 - PM2.5 Ranking | AirVisual". www.iqair.com. Retrieved 1 February 2022.

[7]. Allen, J. L.; Klocke, C.; Morris-Schaffer, K.; Conrad, K.; Sobolewski, M.; Cory-Slechta, D. A. (June 2017). "Cognitive Effects of Air Pollution Exposures and Potential Mechanistic Underpinnings". Current Environmental Health Reports. 4 (2): 180-191. doi:10.1007/s40572-017-0134-3. PMC 5499513. PMID 28435996.

[8]. Jump up to: Ghosh, Rakesh; Causey, Kate; Burkart, Katrin; Wozniak, Sara; Cohen, Aaron; Brauer, Michael (28 September 2021). "Ambient and household PM2.5 pollution and adverse perinatal outcomes: A meta-regression and analysis of attributable global burden for 204 countries and territories". PLOS Medicine. 18 (9):e1003718. doi:10.1371/journal.pmed.1003718. ISSN 1549-1676. PMC 8478226. PMID 34582444.. 
[9]. Silva, Raquel A; West, J Jason; Zhang, Yuqiang; Anenberg, Susan C; Lamarque, Jean-François; Shindell, Drew T; Collins, William J; Dalsoren, Stig; Faluvegi, Greg; Folberth, Gerd; Horowitz, Larry W; Nagashima, Tatsuya; Naik, Vaishali; Rumbold, Steven; Skeie, Ragnhild; Sudo, Kengo; Takemura, Toshihiko; Bergmann, Daniel; Cameron-Smith, Philip; Cionni, Irene; Doherty, Ruth M; Eyring, Veronika; Josse, Beatrice; MacKenzie, I A; Plummer, David; Righi, Mattia; Stevenson, David S; Strode, Sarah; Szopa, Sophie; Zeng, Guang (2013). "Global premature mortality due to anthropogenic outdoor air pollution and the contribution of past climate change". Environmental Research Letters. 8 (3): 034005. Bibcode:2013ERL.....8c4005S. doi:10.1088/17489326/8/3/034005.

[10]. Lelieveld, J.; Klingmüller, K.; Pozzer, A.; Burnett, R. T.; Haines, A.; Ramanathan, V. (25 March 2019$).$ "Effects of fossil fuel and total anthropogenic emission removal on public health and climate". Proceedings of the National Academy of Sciences of the United States of America. 116 (15): 7192-7197. Bibcode:2019PNAS..116.7192L. doi:10.1073/pnas.1819989116. PMC 6462052. PMID 30910976. S2CID 85515425.

[11]. Jump up to:a b Lelieveld, Jos; Pozzer, Andrea; Pöschl, Ulrich; Fnais, Mohammed; Haines, Andy; Münzel, Thomas (1 September 2020). "Loss of life expectancy from air pollution compared to other risk factors: a worldwide perspective". Cardiovascular Research. 116 (11): 1910-1917. doi:10.1093/cvr/cvaa025. ISSN 00086363. PMC 7449554. PMID 32123898.

[12]. "Energy and Air Pollution" (PDF). Iea.org. Archived from the original (PDF) on 11 October 2019. Retrieved 12 March 2019.

[13]. "Study Links 6.5 Million Deaths Each Year to Air Pollution". The New York Times. 26 June 2016. Retrieved 27 June 2016.

[14]. "Reports". WorstPolluted.org. Archived from the original on 11 August 2010. Retrieved 29 August 2010.

[15]. "Cheap air pollution monitors help plot your walk". European Investment Bank. Retrieved 18 May 2021.

[16]. "9 out of 10 people worldwide breathe polluted air, but more countries are taking action". www.who.int. Retrieved 18 May 2021.

[17]. "Assessing the risks to health from air pollution-European Environment Agency". www.eea.europa.eu. Retrieved 18 May 2021.

[18]. Unnikrishnan, S., Iqbal, R., Singh, A., \&Nimkar, I. M. (2015). Safety management practices in small and medium enterprises in India. Safety and health at work, 6(1), 46- 55.

[19]. Baybutt, P. (2013). The role of people and human factors in performing process hazard analysis. Journal of Loss Prevention in the Process Industries, 26(6), 1352-1365.

[20]. Risk assessment of occupational injuries using Accident Severity Grade. [In:] Safety Science, 6. Ebrahimzadih, M., Halvani, G.H., Darvishi, E., and Froghinasab, F. (2015).

[21]. Duijm, Nijs Jan. "Hazard analysis of technologies for disposing explosive waste." Journal of hazardous materials 90.2 (2002): 123-135.

[22]. Hazard Identification and Risk Assessment of industries processing's Hazard Identification Risk Assessment and control Procedure 2008.pdf. 